\title{
Descriptive Epidemiology of Brain and Central Nervous System Tumours: Results from Iran National Cancer Registry, 2010-2014
}

\author{
Amir Salimi, ${ }^{1}$ Alireza Zali, ${ }^{2}$ Amir Saeid Seddighi, ${ }^{2}$ Afsoun Seddighi, ${ }^{2}$ Shakila Meshkat, ${ }^{3}$ \\ Morteza Hosseini, ${ }^{2}$ Amir Nikouei, ${ }^{2}$ and Mohammad Esmaeil Akbari (D) ${ }^{1}$ \\ ${ }^{1}$ Cancer Research Center, Shahid Beheshti University of Medical Sciences, Tehran, Iran \\ ${ }^{2}$ Functional Neurosurgical Research Center, Shahid Beheshti University of Medical Sciences, Tehran, Iran \\ ${ }^{3}$ School of Medicine, Tehran University of Medical Sciences, Tehran, Iran
}

Correspondence should be addressed to Mohammad Esmaeil Akbari; drakbari.drakbari@gmail.com

Received 3 April 2020; Revised 22 July 2020; Accepted 5 August 2020; Published 18 September 2020

Academic Editor: Eleanor Kane

Copyright ( 2020 Amir Salimi et al. This is an open access article distributed under the Creative Commons Attribution License, which permits unrestricted use, distribution, and reproduction in any medium, provided the original work is properly cited.

\begin{abstract}
Background. Central nervous system (CNS) tumours account for only 1-2\% of cancer incidence but are a major reason for mortality and morbidity due to malignancies. Recent studies show an increase in the rate of CNS tumours worldwide, especially in developing countries. Moreover, there is significant heterogeneity in epidemiological patterns worldwide. This study is aimed at representing nationwide epidemiology of CNS tumours in Iran. Methods. Iran National Cancer Registry 2010-2014 data were reviewed for CNS tumours. The epidemiological rates were calculated for both genders and all age groups using the 2011 census information. Results. Out of 17345 cases, $58.5 \%$ were men and $41.5 \%$ were women. The mean age was 45.55 years ranging from less than 1 month to 100 years old. Average total age-standardized incidence rate (ASR) was 5.19 for primary tumours. The annual percent change (APC) was $14.23 \%$ during the study period. The most frequent site and histology recorded were brain, NOS and diffuse astrocytic, respectively. Geographical distribution showed about five-fold difference in ASRs between different provinces. Conclusion. The overall ASR calculated was higher than the global rate in 2012 but lower than that of most developed countries, showing an increasing trend which may be due to either advances in diagnosing or risk factor augmentation. The mean age and incident rates were higher than those of previous reports in Iran.
\end{abstract}

\section{Introduction}

Central nervous system (CNS) tumours are much less prevalent, accounting for only $1-2 \%$ of the total cancer incidence. However, they represent a major source of mortality and morbidity [1-3]. In the United States, CNS cancers represent $1.4 \%$ of newly diagnosed cancers and $2.7 \%$ of cancer mortality [4]. Recent studies show an increase in the prevalence of CNS tumours worldwide $[2,5]$. Based on the most recent estimates, each year, more than 296000 new cases (1.6\% of overall cancer incidence) are diagnosed worldwide, and more than 241000 individuals die due to CNS tumours $(2.5 \%$ of overall cancer mortality) $[1,6,7]$ with men showing a higher incidence rate (IR) (4.2 in 100000 inhabitants) than that of women (3.6 in 100000 inhabitants) [6]. The IR of all primary CNS tumours ranges from $17.6 / 10^{5}$ to $22.0 / 10^{5}$ in America $[8]$ and Europe $[7,9,10]$.
Central nervous system tumour is typically defined as brain and spine tumours; however, the International Classification of Diseases for Oncology third edition (ICD-O-3) defines meninges, pineal gland, pituitary gland, and nerves as CNS tumours as well [11].

There is significant heterogeneity in the epidemiology, incidence, mortality, and histological spectrum of CNS tumours across different regions of the world $[3,12]$. The probable reason for such differences in epidemiologic patterns is yet unclear, but differences in environment, genetics, culture, age, and access to health resources could be considered $[1,2]$. Comprehensive and systematic epidemiological studies can further our knowledge of such influences worldwide.

Developed countries conducted a number of comprehensive epidemiological studies on CNS tumours [5, 8, 13-17]. In contrast, in developing countries including Iran [18-20], 
scattered studies have been conducted. There are not any comprehensive nationwide studies in this area [21-28]. Thus, in the current study, we aimed to present a nationwide CNS tumour epidemiology for all age groups in all provinces of Iran as well as the epidemiologic trend during the study period based on Iran National Cancer Registry (INCR) data.

\section{Material and Methods}

2.1. Data Source. The study included patients who were diagnosed with central nervous system cancer from 2010 to 2014. The patients were identified by ICD-O-3 codes (Tables 1 and 2) through the Iran National Cancer Registry. National cancer registry raw data were reviewed for all registered CNS tumours from 2010 to 2014. Based on histology reports, some of the patients were categorized as "secondary tumours" and "undetermined secondary or primary" but most of the patients were categorized as "primary tumours" and we focused on them in our study. Reporting benign CNS tumours is not compulsory and systematic yet, but if reported by a center, they would be involved in the INCR data.

2.2. Design. We conducted a nationwide population-based study on national cancer registry data on CNS tumours over 5 years from 2010 to 2014. Duplicate cases were first identified according to patients' names, family, tunour type, tumour location, and sex, then were excluded from the study. Data were categorized based on WHO classification of CNS tumours histologies reported by Louis et al. [29]. Population data were obtained from the last 2011 census On the National Institute of Statistics of Iran webpage (https://amar.org.ir/), and the Segi-Doll standard population data were obtained from The Global Cancer Observatory (GCO) website [30] to perform ASR calculations.

2.3. Statistical Analysis. Categorical data are presented as numbers and percentages. To compare categorical and continuous data between male and female groups, chi-squared and independent-sample $t$-tests were applied.

The last 2011 census of population information was used to calculate (age- and gender-specific) crude incidence rates (CIRs) per 100000 individuals. To obtain annual incidence rates from 2010 to 2014, the estimated midyear population was used as denominator. The Segi-Doll standard population data were used to calculate age-standardized rates (ASRs) by the direct standardization method.

The incidence rates are presented with 95\% confidence interval $(95 \% \mathrm{CI})$. To investigate the trend of the rates during this period of time, a log-linear model was fitted and the average annual percent change (APC) was calculated based on the model parameter [31]. All calculations and statistical analysis were carried out using Microsoft Excel 2013 and R statistical software, version 3.2.1. The significance level was set at 0.05 .

2.4. Ethical Approval. This study was approved by the Shahid Beheshti University of Medical Sciences Ethics Committee.
TABLE 1: ICD-O-3 topography (site) codes.

\begin{tabular}{lc}
\hline Site & ICD-O-3 site codes \\
\hline Meninges & C70.0, C70.1, C70.9 \\
Cerebrum & C71.0 \\
Frontal lobe of brain & C71.1 \\
Temporal lobe of brain & C71.2 \\
Parietal lobe of brain & C71.3 \\
Occipital lobe of brain & C71.4 \\
Ventricle & C71.5 \\
Cerebellum & C71.6 \\
Brainstem & $\mathrm{C} 71.7$ \\
Overlapping lesion of brain & $\mathrm{C} 71.8$ \\
Brain, NOS & $\mathrm{C} 71.9$ \\
Spinal cord & $\mathrm{C} 72.0$ \\
Cauda equina & $\mathrm{C} 72.1$ \\
Cranial nerves & $\mathrm{C} 72.2, \mathrm{C} 72.3, \mathrm{C} 72.4, \mathrm{C} 72.5$ \\
Overlapping lesion of brain and & $\mathrm{C} 72.8$ \\
central nervous system & $\mathrm{C} 72.9$ \\
Nervous system, NOS &
\end{tabular}

\section{Results}

3.1. Overall Incidence. In this study, we reviewed 17345 incident cases of CNS tumours from 2010 to 2014 . Only $50.4 \%$ of data were microscopically verified (MV). Out of 17345 cases, 10151 were men (58.5\%) and 7194 were women (41.5\%).

Based on the nature of tumours, we divided them into three major groups: (i) primary, (ii) secondary, and (iii) undetermined whether secondary or primary (SorP). The mean age at diagnosis for patients in the primary, secondary, and undetermined groups was $45.55 \pm 21.46,49.78 \pm 19.17$, and $35.44 \pm 21.95$, respectively, with a statistically significant difference between them ( $p$ value $<0.001$ ).

The highest average ASR during the study period was observed among primary tumours $(5.19 ; 95 \%$ CI (4.99-5.38)) in both men (5.56 (5.41-5.71)) and women (3.93 (3.814.06)). Secondary and secondary or primary (SorP) had ASRs of 0.21 and 0.04 , respectively. Annex 1 shows the number of patients in the study period in each age category separated by gender. Patients under 1 year of age are presented separately due to the importance of CNS tumours in this group of patients. Annex 2 depicts the annual age-specific CIR and the number of patients per year from 2010 to 2014 and the average CIR during the entire study period. Hereafter, all rates and reports are for 16547 primary tumour cases.

Mean age at diagnosis was $45.54(\mathrm{SD}=21.45)$; the oldest patient was 100 years old and the youngest patient was a neonate. Out of 16547 cases, only 8115 (51.1\%) were microscopically verified, 9695 (58.6\%) were male, and 6852 (41.4\%) were female.

3.2. Age-Standardized and Gender-Specific Incidence Rate of Primary Tumours. Table 3 depicts the annual ASRs and the number of patients per year from 2010 to 2014 and the average ASR during the entire study period. The average ASR was 5.19 (4.99-5.38) per 100000 individuals per 
TABLE 2: ICD-O-3 histology codes.

\begin{tabular}{|c|c|}
\hline Histology & ICD-O-3 histology codes \\
\hline Diffuse astrocytic and oligodendroglial tumours & $9380,9382,9400,9401,9411,9440,9441,9442,9450,9451$ \\
\hline Other astrocytic tumours & 9421,9424 \\
\hline Ependymal tumours & $9383,9391,9392,9393$ \\
\hline Other gliomas & 9430 \\
\hline Choroid plexus tumours & 9390 \\
\hline Embryonal tumours & $9470,9471,9473,9474,9490,9500,9501,9502,9521$ \\
\hline Tumours of cranial and paraspinal nerves & 9560,9540 \\
\hline Meningioma & $9530,9531,9534,9537,9538$ \\
\hline Mesenchymal, nonmeningothelial tumours & $\begin{array}{c}8802,8810,8815,8850,8851,8890,8900,9120,9133,9140,9161, \\
9170,9180,9220,9240,9243,9364,9370,9371\end{array}$ \\
\hline Melanocytic tumours & 8720 \\
\hline Lymphomas & $9590,9591,9596,9670,9675,9680,9684,9699,9702$ \\
\hline Germ cell tumours & $9060,9064,9065,9071,9080,9081,9085$ \\
\hline Others & 9505,9750 \\
\hline Unspecified & 8000,8001 \\
\hline
\end{tabular}

TABLE 3: Distribution of tumours in different sites (topography) and patients' mean age.

\begin{tabular}{|c|c|c|c|c|}
\hline Location & Total number (\%) & Male mean age & Female mean age & $p$ value \\
\hline Meninges & $408(2.5 \%)$ & 53.4 & 50 & 0.09 \\
\hline Cerebrum & $521(3.1 \%)$ & 43.4 & 40.8 & 0.18 \\
\hline Frontal lobe & $1316(8 \%)$ & 44.7 & 45.6 & 0.37 \\
\hline Temporal lobe & $1039(6.3 \%)$ & 46.9 & 45.2 & 0.16 \\
\hline Parietal lobe & $823(5 \%)$ & 47.9 & 46.7 & 0.35 \\
\hline Occipital lobe & $182(1.1 \%)$ & 49.5 & 44.1 & 0.05 \\
\hline Ventricle & $147(0.9 \%)$ & 35.5 & 38 & 0.47 \\
\hline Cerebellum & $633(3.8 \%)$ & 29.2 & 33.1 & 0.03 \\
\hline Brainstem & $182(1.1 \%)$ & 31 & 25.6 & 0.09 \\
\hline Brain, NOS & $8968(54.2 \%)$ & 46.2 & 46.2 & 0.84 \\
\hline Spinal cord & $515(3.1 \%)$ & 42.3 & 44.5 & 0.24 \\
\hline Cranial nerves & $34(0.2 \%)$ & 40.4 & 32.2 & 0.36 \\
\hline Overlapping brain and central nervous system & $45(0.3 \%)$ & 52.4 & 49.6 & 0.66 \\
\hline Missing & $200(1.2 \%)$ & 43.7 & 40.5 & 0.32 \\
\hline Overlapping brain & $382(2.3 \%)$ & 47 & 44.5 & 0.20 \\
\hline Cauda equina & $7(0.04 \%)$ & 43.7 & 46 & 0.91 \\
\hline Nervous system, NOS & $1145(6.9 \%)$ & 51.8 & 51.2 & 0.67 \\
\hline
\end{tabular}

year. The highest CIR among age groups was 16.25 (for the 75-79y group) and the lowest was 1.34 (for the 1014-year-old age group). The annual CIR and the average CIRs are presented by age group in Annex 2. The annual CIR and the average CIRs were depicted by age group and gender in Figure 1.

The total ASR of primary tumours in the entire study period was 5.19 (4.99-5.38), and the total ASRs were 5.56 (5.41-5.71) and 3.93 (3.81-4.06) for men and women, respectively (Table 3$)$. The ASR increased from 3.43 (3.33-3.54) in 2010 to 5.60 (5.47-5.72) in 2014. According to the Poisson regression model result, a significant rising trend was observed in the total ASR rates during this period ( $p=0.001$ for trend). The annual percent change (APC) was $14.23 \%$ during the study period. The ASR changed from 3.96 (3.84-4.07) in 2010 to 6.48 (6.34-6.62) in 2014 for men and from $2.92(2.82-3.01)$ in 2010 to 4.76 (4.64-4.88) in 2014 for women. During the study period, there was no statistically significant trend of ASR among men $(p=0.211)$, but an increasing trend of ASR was observed among women $(p<001)$. APC was $14.32 \%$ and $14.25 \%$ for men and women, respectively. 
2010

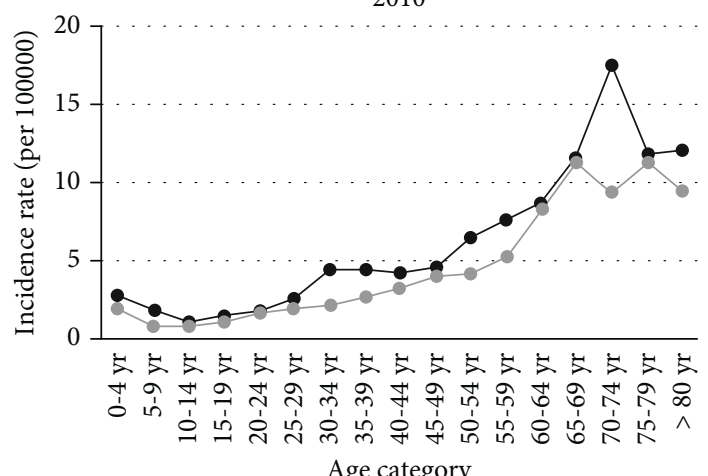

2012

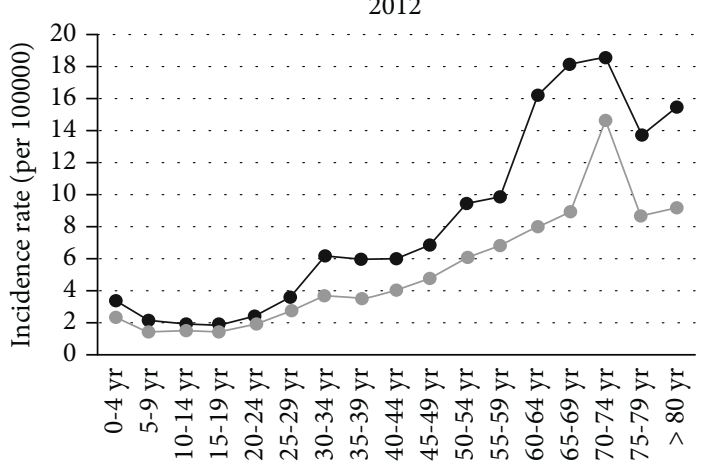

Age category

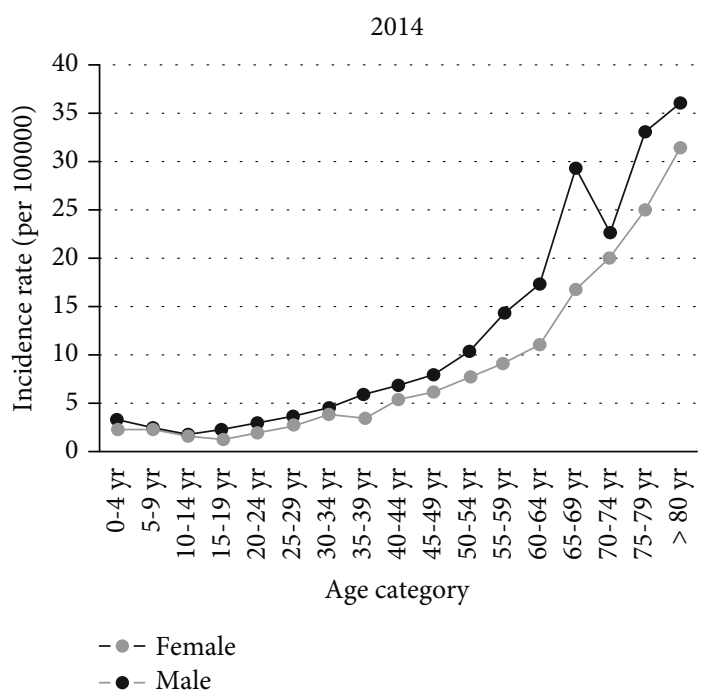

2011

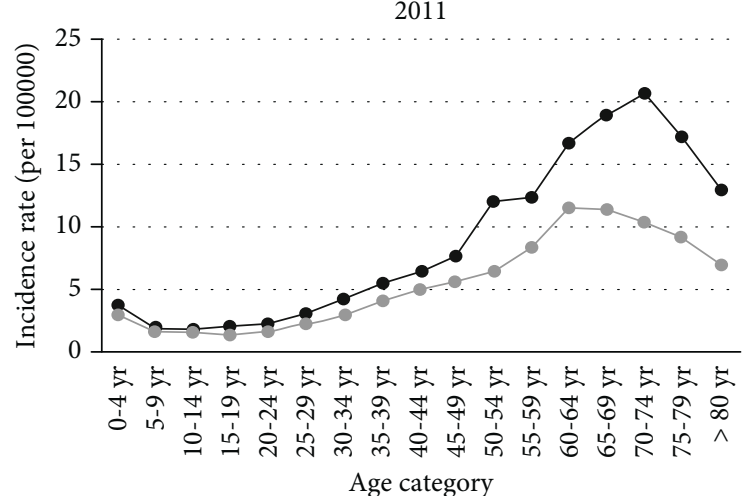

2013

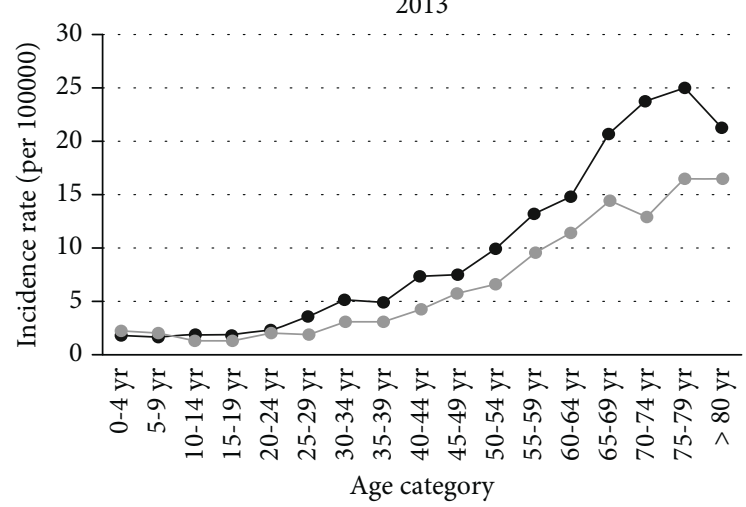

Total

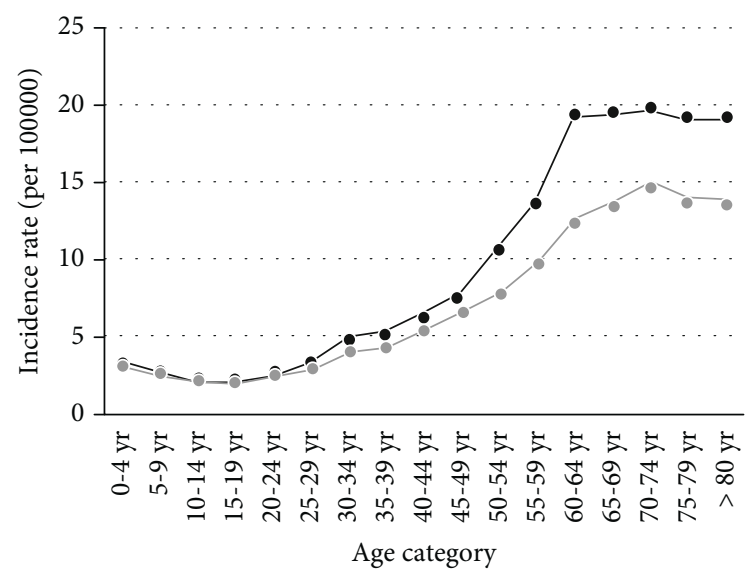

FIgURE 1: Crude incidence rates by gender and age in each year and the whole period.

3.3. Tumour Site (Topography). The most common recorded sites are as follows: brain, NOS; frontal lobe; nervous system, NOS; and temporal lobe. Each comprise 54.2\%, 8\%, 6.9\%\%, and $6.3 \%$ of all data, respectively. A statistically significant difference was observed between the genders' distribution of tumour location regarding the frontal lobe, temporal lobe, parietal lobe, meninges, and brainstem. Men had significantly more tumours in the frontal lobe, temporal lobe, and parietal lobe, and women had more tumours in the brainstem and meninges $(p<0.05)$. Men with tumours in the occipital lobe were significantly older than women $(p<0.05)$, while women with tumours in the cerebellum were significantly older than men $(p<0.05)$. Table 4 shows the mean age and number of patients based on tumour location in both genders with a significant difference between females and males in the occipital lobe and cerebellum.

3.4. Tumour Histology. The number of patients and ASRs are presented in Table 5 . The most common histology subgroups are diffuse astrocytic (48.36\%), unspecified malignancy (32.32\%), and embryonal tumours (4.55\%) with ASRs of $2.40,2.04$, and 0.23 , respectively. 
TABle 4: Age-standardized incidence rate trend.

\begin{tabular}{lccccccccc}
\hline Year & $N$ & $\begin{array}{c}\text { Total } \\
\text { ASR }^{*}\end{array}$ & $95 \%$ CI & $N$ & ASR* & 95\% CI & Nemale & ASR & 95\% CI \\
\hline 2010 & 2380 & 3.43 & $3.33-3.54$ & 1381 & 3.96 & $3.84-4.07$ & 999 & 2.92 & $2.82-3.01$ \\
2011 & 3243 & 4.64 & $4.52-4.77$ & 1927 & 5.51 & $5.39-5.64$ & 1316 & 3.78 & $3.67-4.39$ \\
2012 & 3124 & 4.19 & $4.08-4.31$ & 1877 & 5.12 & $5.57-6.09$ & 1247 & 3.30 & $3.20-3.40$ \\
2013 & 3523 & 4.69 & $4.57-4.81$ & 2074 & 5.51 & $5.39-5.64$ & 1449 & 3.90 & $3.79-4.01$ \\
2014 & 4277 & 5.60 & $5.47-5.72$ & 2436 & 6.48 & $6.34-6.62$ & 1841 & 4.76 & $4.64-4.88$ \\
Total & 16547 & 5.19 & $4.99-5.38$ & 9695 & 5.56 & $5.41-5.71$ & 6852 & 3.93 & $3.81-4.06$ \\
$p$ value & & $<0.001$ & & 0.723 & & & & 0.025 \\
\hline
\end{tabular}

${ }^{*}$ Age-standardized incidence rate.

3.5. Geographic Distribution. Table 6 and Figure 2 show the geographical distribution of CNS tumours in all 31 provinces of Iran based on their average ASRs. Unlike other provinces, the Qom province showed a female predominance. Kohgiluyeh and Boyer-Ahmad and Bushehr provinces had male to female ratios higher than 2, and Qom showed a female predilection in the number of patients.

\section{Discussion}

In this study, we aimed to provide nationwide descriptive epidemiology of CNS tumours among the Iranian population using INCR data. ASRs were calculated using the Segi-Doll standard population to make comparisons more feasible. Hasanpour-Heidari et al. reported completeness of $96.3 \%$ for CNS tumours in Golestan province, which was the best rate among other groups of tumours. Mohammadi et al. reported INCR completeness of $71.2 \%$ and $59.9 \%$ for men and women, respectively, regarding all types of registered tumours $[32,33]$.

The average ASR for all primary CNS tumours registered from 2010 to 2014 was 5.19 (4.99-5.38) per 100000 individuals per year, which was higher than the 2012 global rate of 3.4 [31]. However, our national 2014 ASR increased to 5.19, which was higher than the global rate in 2016 but lower than most developed countries' rates [1, 2, 5, 8, 13, 14, 34]. During 2010-2014, average ASRs were 5.56 and 3.93 for men and women, respectively. Miranda-Filho et al. applied data from 96 registries in 39 countries to evaluate CNS tumours in adults ( $>15$ y); Brazil, Croatia, Thailand, and Uganda showed the highest ASR for men (=13.3), highest ASR for women $(=12)$, lowest ASR for men $(=2.4)$, and lowest ASR for women $(=1)$, respectively [35].

CNS tumours' ASR demonstrated an annual percentage change of $14.23 \%$ during the study period. This incidence surge and a high APC in Iran like other developing countries could be attributed to advances in neuroimaging, neuropathology, and neurosurgery [36-38] or changes in lifestyle, population pyramid, and stronger registration over time $[35,39]$. Other reports from Iran reported high APC rates; Darabi et al. reported an APC of $16.7 \%$ and $20 \%$ for stomach tumours and colorectal tumours, respectively [40]. Leukemia incidence APC was $19.9 \%$ in Koohi et al.'s evaluation [41], and Pakzad et al. calculated an APC of $17.3 \%$ for prostate tumours [42].

Higher CT scan utilization leads to more diagnosis, and it also has more ionizing emissions than plain radiographs [43] and shows association with CNS tumours [44]. A recent report showed that the number of CT scans performed per each emergency room visit in an Iranian hospital in 2016 was about three times higher than world rates [45].

Although the highest rates of CNS tumours were observed in high-middle followed by the high quintile sociodemographic index (SDI), developed countries had negative APC rates in their recent evaluations $[2,34]$, which comes after high APC rates in the late 20th century. Such decreasing rates might be the result of development in early diagnosis and availability of more efficient treatments for nonmalignant tumours or the separation of nonmalignant tumours in recent studies [35].

In a systematic review of primary CNS tumours in Iran from 2000 to 2009, performed by Jazayeri et al., the ASRs were 4.16 for men and 3.46 for women [23]; these are lower than the ASRs in our study which show an ascending trend. Jordan represented a total crude incidence rate of 5.01 for all malignant and nonmalignant CNS tumours in 2011 and 2012 [19].

The mean age at diagnosis was 45.54 years in our study which is higher than that of other studies in Iran [21, 2327] and Jordan [19] but is lower than that of other developed countries which seems to be related to population structure changes. The preponderance of males among CNS tumour patients in our study is in accordance with the global estimates in 2012 (1.41 compared with $1.2 \mathrm{~m} / \mathrm{f}$ ratio) [31] and the estimates in most of other studies in the world that represent male to female ratios between 1 and 2.7 [35]; however, some studies showed female predominance similar to Qom province [19, 22, 46]. The possible hypothesis for male preponderance is sex hormones and adverse working conditions such as exposure to chemicals and pesticides [47].

Our findings on the histology of tumours are not possibly conclusive enough due to notably high rates of unspecified tumours (mostly M 8000.3 and M 8001.3 codes), which are likely a reflection of lack of advanced diagnostic facilities particularly in rural areas that indicates high rates of astrocytic and oligodendroglia tumours. These findings are in line with 


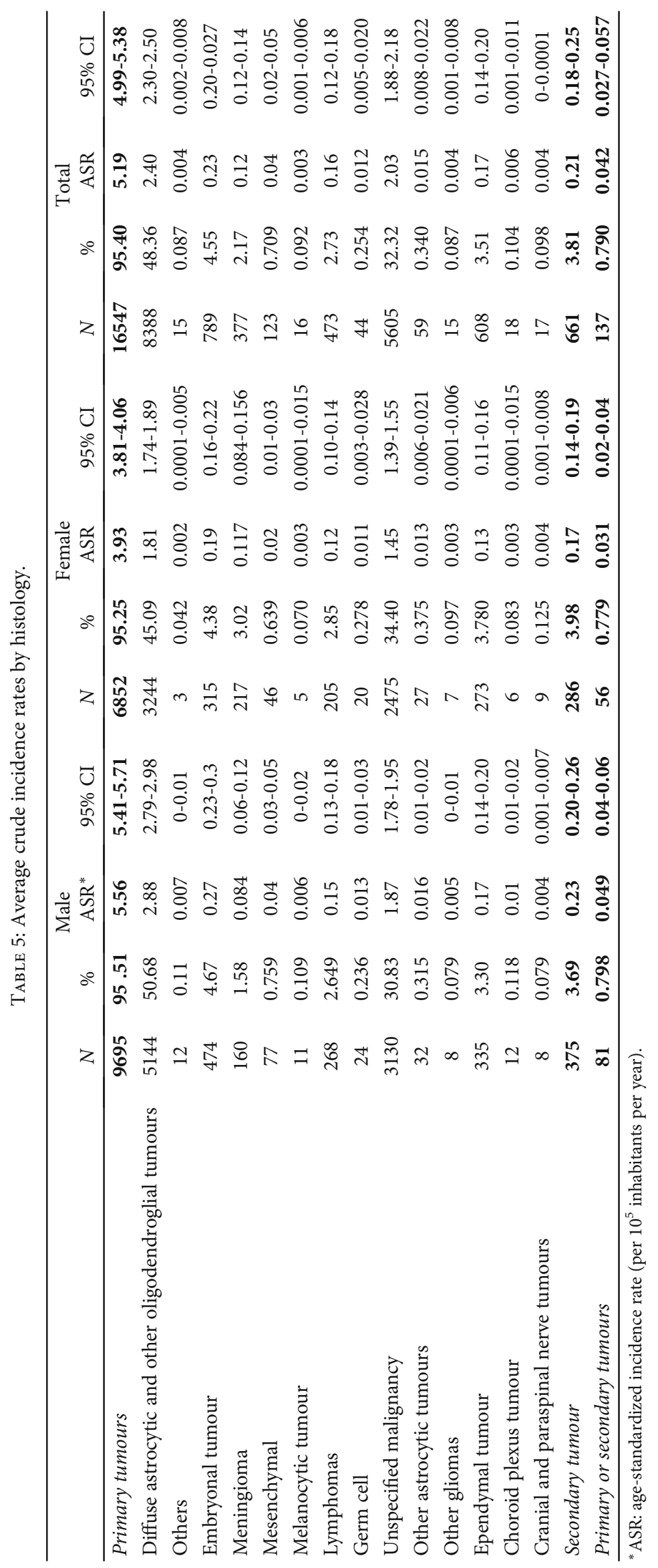


TABLE 6: Geographical distribution of CNS tumours by provinces.

\begin{tabular}{|c|c|c|c|c|c|c|c|c|c|}
\hline \multirow{2}{*}{ Region } & \multirow{2}{*}{ Province } & \multicolumn{3}{|c|}{ ASR } & \multicolumn{4}{|c|}{ Number } & \multirow{2}{*}{ Mean age } \\
\hline & & Male & Female & Total & Male & Female & Total & $\mathrm{M} / \mathrm{F}$ ratio & \\
\hline \multirow{9}{*}{ North/North West } & Ardebil & 4.72 & 4.04 & 4.61 & 132 & 104 & 236 & 1.3 & 42.5 \\
\hline & Golestan & 3.59 & 2.54 & 3.20 & 134 & 87 & 221 & 1.5 & 43.5 \\
\hline & Guilan & 4.89 & 4.09 & 4.73 & 324 & 245 & 569 & 1.3 & 52.4 \\
\hline & Mazandaran & 2.85 & 1.98 & 2.41 & 213 & 153 & 366 & 1.4 & 44.9 \\
\hline & North Khorasan & 4.56 & 3.38 & 4.48 & 72 & 60 & 132 & 1.2 & 44.5 \\
\hline & East Azarbaijan & 2.72 & 2.37 & 2.85 & 258 & 225 & 483 & 1.1 & 49.9 \\
\hline & Kordestan & 4.29 & 3.64 & 3.95 & 156 & 124 & 280 & 1.3 & 43.8 \\
\hline & West Azarbaijan & 4.01 & 3.09 & 3.54 & 276 & 221 & 497 & 1.2 & 46.6 \\
\hline & Zanjan & 3.87 & 3.20 & 3.53 & 96 & 79 & 175 & 1.2 & 44.1 \\
\hline \multirow{5}{*}{ West } & Hamedan & 4.27 & 3.32 & 3.80 & 189 & 128 & 317 & 1.5 & 46 \\
\hline & Ilam & 3.16 & 1.68 & 2.52 & 37 & 20 & 57 & 1.9 & 52.3 \\
\hline & Kermanshah & 3.85 & 1.83 & 2.39 & 131 & 88 & 219 & 1.5 & 43 \\
\hline & Khouzestan & 6.55 & 4.89 & 5.84 & 623 & 452 & 1075 & 1.4 & 43.1 \\
\hline & Lorestan & 7.08 & 4.69 & 6.06 & 273 & 172 & 445 & 1.6 & 46.3 \\
\hline \multirow{11}{*}{ Center } & Alborz & 4.67 & 2.61 & 3.71 & 262 & 137 & 399 & 1.9 & 48.5 \\
\hline & Chaharmahal and Bakhtiari & 3.34 & 2.25 & 2.89 & 65 & 47 & 112 & 1.4 & 41.4 \\
\hline & Qazvin & 3.49 & 2.28 & 2.88 & 95 & 63 & 158 & 1.5 & 46.5 \\
\hline & Isfahan & 6.87 & 5.27 & 6.35 & 808 & 568 & 1376 & 1.4 & 50.6 \\
\hline & Kerman & 4.82 & 3.76 & 4.32 & 292 & 234 & 526 & 1.2 & 44.1 \\
\hline & Kohgiluyeh and Booyer Ahmad & 4.84 & 2.89 & 3.87 & 78 & 39 & 117 & 2 & 34.9 \\
\hline & Markazi & 8.46 & 6.15 & 7.29 & 305 & 217 & 522 & 1.4 & 51.9 \\
\hline & Semnan & 5.28 & 4.12 & 4.69 & 79 & 58 & 137 & 1.4 & 50 \\
\hline & Tehran & 5.33 & 3.71 & 4.52 & 1618 & 1098 & 2716 & 1.5 & 45.1 \\
\hline & Yazd & 10.45 & 9.33 & 9.86 & 270 & 229 & 499 & 1.2 & 48.3 \\
\hline & Qom & 1.51 & 2.09 & 1.85 & 43 & 52 & 95 & 0.8 & 45.9 \\
\hline \multirow{3}{*}{ East } & Razavi Khorasan & 6.31 & 4.74 & 5.59 & 838 & 615 & 1453 & 1.4 & 44.7 \\
\hline & Sistan and Baluchestan & 2.75 & 2.12 & 2.44 & 126 & 91 & 217 & 1.4 & 37.2 \\
\hline & South Khorasan & 3.42 & 2.20 & 2.81 & 48 & 31 & 79 & 1.5 & 41.5 \\
\hline \multirow{3}{*}{ South } & Bushehr & 3.83 & 1.76 & 2.83 & 88 & 36 & 124 & 2.4 & 40.6 \\
\hline & Fars & 8.31 & 6.24 & 7.47 & 886 & 626 & 1512 & 1.4 & 46.7 \\
\hline & Hormozgan & 2.77 & 2.42 & 2.58 & 91 & 78 & 169 & 1.2 & 38.9 \\
\hline Unknown & & 0.46 & 0.27 & 0.37 & 789 & 475 & 1264 & 1.7 & 34.1 \\
\hline
\end{tabular}

previous studies conducted in Iran [22, 25, 27]. Lack of a unanimous tumour diagnosis even by skillful pathologists is another reason behind the high rates of unspecified tumours. Another difficulty was in the data analysis phase of the project; we found histology codes that could not be considered primary (adenocarcinomas). Thus, to avoid underestimation, such codes were first categorized into a secondary tumour group or primary/secondary group and then included in our total calculations. However, we reported primary tumours rates separately to make comparisons with other studies unchallenging for readers.

There was a noticeable difference in incidence rates in different provinces across the country; Yazd province had an ASR of 9.86 per 100000 individuals per year, and Qom province had an ASR of 1.85 per 100000 individuals per year.
It showed more than five-fold difference between them, similar to the difference that was observed between different regions in the world [35] and Roshandel et al.'s study of cancer incidence in Iran in 2014 [48]. This result could likely be due to many factors such as differences in the availability of medical facilities, genetics, lifestyle, environmental, and many other probable factors that should be considered in future studies.

There is not enough information on the etiology of CNS tumours except genetics and ionizing radiations as risk factors and a possible carcinogen with unknown effects. Moreover, allergic reactions can decrease the risk of CNS tumours $[49,50]$. Therefore, more comprehensive epidemiological studies are needed to find out the relationship between potential etiologies and epidemiologic diversities. 


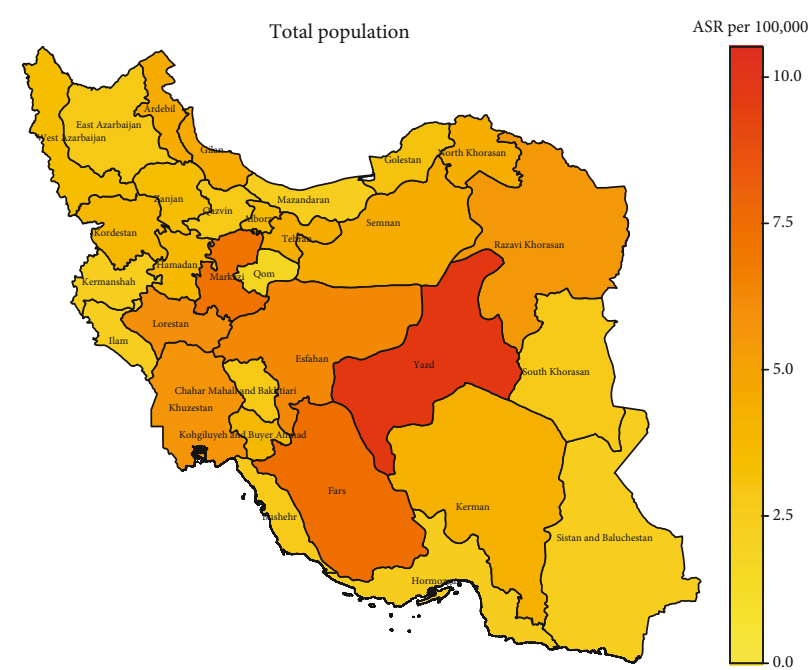

(a)

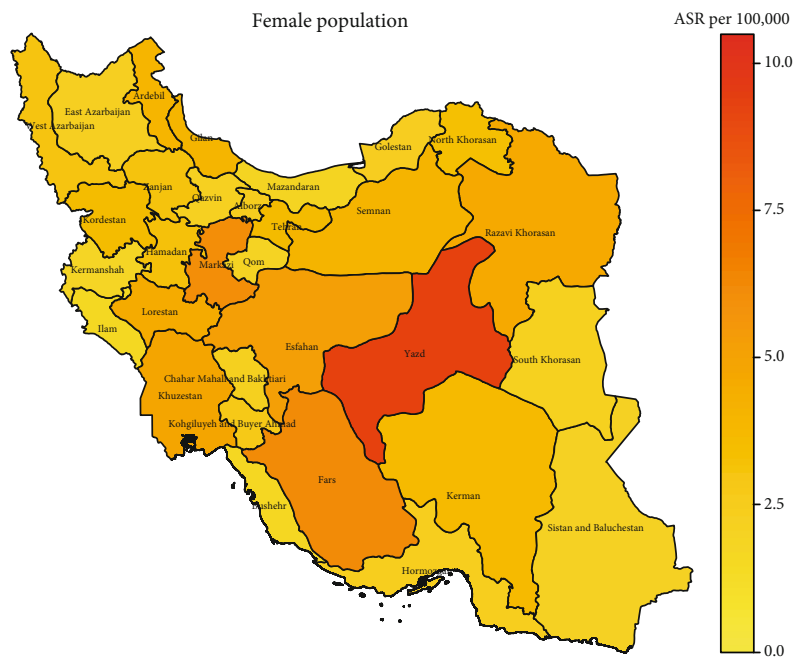

(b)

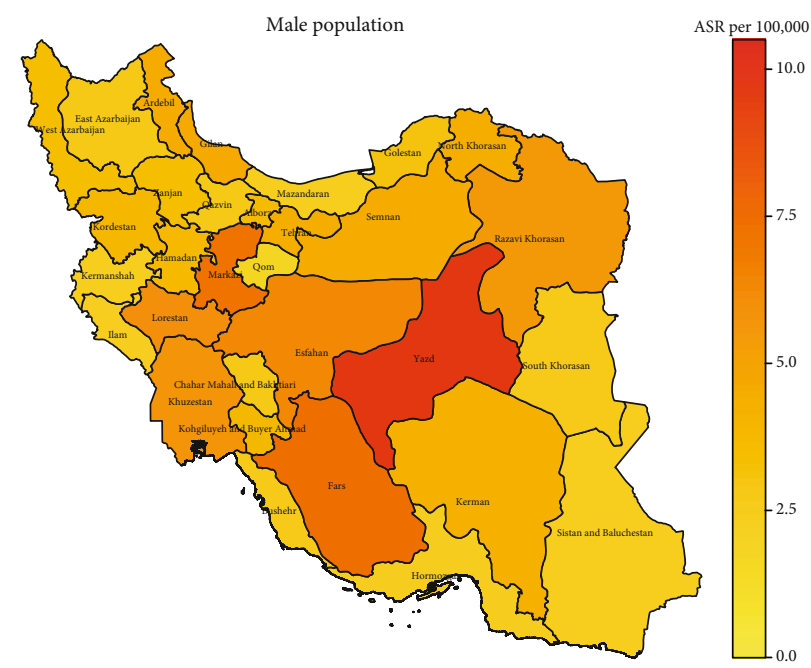

(c)

Figure 2: Geographical distribution of CNS tumours by provinces in the total population (a), in the female population (b), and in the male (c) population. 


\section{Data Availability}

Data are available on demand for those who meet our criteria.

\section{Additional Points}

Key Points. Average total age-standardized incidence rate (ASR) was 5.19 for primary tumours. The annual percent change was $13.69 \%$ during the study period. Geographical distribution showed five-fold difference in ASR among provinces.

\section{Conflicts of Interest}

The authors declare that they have no conflicts of interest.

\section{Acknowledgments}

The authors acknowledge the Iran National Cancer Registry and Cancer Research Center and their staff for their kind contribution to data gathering.

\section{Supplementary Materials}

Annex 1: depicts the number of patients in each age group by gender in the whole study on an age-gender pyramid. Annex 2: includes crude incidence rates by age groups and year. (Supplementary Materials)

\section{References}

[1] F. Bray, J. Ferlay, I. Soerjomataram, R. L. Siegel, L. A. Torre, and A. Jemal, "Global cancer statistics 2018: GLOBOCAN estimates of incidence and mortality worldwide for 36 cancers in 185 countries," CA: A Cancer Journal for Clinicians, vol. 68, no. 6, pp. 394-424, 2018.

[2] V. L. Feigin, E. Nichols, T. Alam et al., "Global, regional, and national burden of neurological disorders, 1990-2016: a systematic analysis for the Global Burden of Disease Study 2016," The Lancet Neurology, vol. 18, no. 5, pp. 459-480, 2019.

[3] T. Gupta, R. Achari, A. Chatterjee et al., "Comparison of epidemiology and outcomes in neuro-oncology between the east and the west: challenges and opportunities," Clinical Oncology (Royal College of Radiologists), vol. 31, no. 8, pp. 539-548, 2019.

[4] R. L. Siegel, K. D. Miller, and A. Jemal, "Cancer statistics, 2016," CA: A Cancer Journal for Clinicians, vol. 66, no. 1, pp. 7-30, 2016.

[5] C. Pouchieu, A. Gruber, E. Berteaud et al., "Increasing incidence of central nervous system (CNS) tumors (2000-2012): findings from a population based registry in Gironde (France)," BMC Cancer, vol. 18, no. 1, pp. 653-653, 2018.

[6] F. Bray, M. Colombet, L. Mery et al., Cancer Incidence in Five Continents, Vol. XI (electronic version), Lyon, IARC, 2017, http://ci5.iarc.fr last accessed on [ August 14, 2020].

[7] R. Stupp, W. P. Mason, M. van den Bent et al., "Radiotherapy plus concomitant and adjuvant temozolomide for glioblastoma," The New England Journal of Medicine, vol. 352, no. 10, pp. 987-996, 2005.

[8] Q. T. Ostrom, H. Gittleman, J. Fulop et al., "CBTRUS statistical report: primary brain and central nervous system tumors diagnosed in the United States in 2008-2012," Neuro-Oncology, vol. 17, Supplement 4, pp. iv1-iv62, 2015.

[9] L. Hardell, M. Carlberg, F. Soderqvist, and K. H. Mild, "Casecontrol study of the association between malignant brain tumours diagnosed between 2007 and 2009 and mobile and cordless phone use," International Journal of Oncology, vol. 43, no. 6, pp. 1833-1845, 2013.

[10] D. N. Louis, H. Ohgaki, O. D. Wiestler et al., “The 2007 WHO classification of tumours of the central nervous system," Acta Neuropathologica, vol. 114, no. 2, pp. 97-109, 2007.

[11] A. Fritz, Percy, Constance et al.et al., International Classification of Diseases for Oncology, World Health Organization, 3rd edition, 2000.

[12] M. L. Bondy, M. E. Scheurer, B. Malmer et al., "Brain tumor epidemiology: consensus from the Brain Tumor Epidemiology Consortium," Cancer, vol. 113, no. S7, pp. 1953-1968, 2008.

[13] R. H. Dahlrot, F. R. Poulsen, N. N. T. T. Nguyen et al., "Trends in tumors in the central nervous system in elderly in Denmark, 2008-2012," Acta Oncologica, vol. 55, Supplement 1, pp. 9197, 2016.

[14] A. Darlix, S. Zouaoui, V. Rigau et al., "Epidemiology for primary brain tumors: a nationwide population-based study," Journal of Neuro-Oncology, vol. 131, no. 3, pp. 525-546, 2017.

[15] C. H. Lee, K. W. Jung, H. Yoo, S. Park, and S. H. Lee, "Epidemiology of primary brain and central nervous system tumors in Korea," Journal of Korean Neurosurgical Association, vol. 48, no. 2, pp. 145-152, 2010.

[16] E. V. Walker, F. G. Davis, CBTR founding affiliates et al., "Malignant primary brain and other central nervous system tumors diagnosed in Canada from 2009 to 2013," NeuroOncology, vol. 21, no. 3, pp. 360-369, 2019.

[17] A. Philips, D. L. Henshaw, G. Lamburn, and M. J. O’Carroll, "Brain Tumours: Rise in Glioblastoma Multiforme Incidence in England 1995-2015 Suggests an Adverse Environmental or Lifestyle Factor," Journal of Environmental and Public Health, vol. 2018, Article ID 7910754, 10 pages, 2018.

[18] E. Jedy-Agba, M. P. Curado, O. Ogunbiyi et al., "Cancer incidence in Nigeria: a report from population-based cancer registries," Cancer Epidemiology, vol. 36, no. 5, pp. e271-e278, 2012.

[19] A. F. Tamimi, I. Tamimi, M. Abdelaziz et al., "Epidemiology of malignant and non-malignant primary brain tumors in Jordan," Neuroepidemiology, vol. 45, no. 2, pp. 100-108, 2015.

[20] N. Manoharan, P. K. Julka, and G. K. Rath, "Descriptive epidemiology of primary brain and CNS tumors in Delhi, 20032007," Asian Pacific Journal of Cancer Prevention, vol. 13, no. 2, pp. 637-640, 2012.

[21] S. Beygi, S. Saadat, S. B. Jazayeri, and V. Rahimi-Movaghar, "Epidemiology of pediatric primary malignant central nervous system tumors in Iran: a 10 year report of National Cancer Registry," Cancer Epidemiology, vol. 37, no. 4, pp. 396-401, 2013.

[22] K. Askari, S. Janeshin, M. Mashouf, M. Taherzadeh-Amlashi, and S. M. Seyed-Saadat, "Central nervous system tumors in Guilan, Iran: epidemiological features over 10 years," Caspian Journal of Neurological Sciences, vol. 1, no. 1, pp. 19-26, 2015.

[23] S. B. Jazayeri, V. Rahimi-Movaghar, F. Shokraneh, S. Saadat, and R. Ramezani, "Epidemiology of primary CNS tumors in Iran: a systematic review," Asian Pacific Journal of Cancer Prevention, vol. 14, no. 6, pp. 3979-3985, 2013. 
[24] S. M. Alimohamadi, S. M. Ghodsi, and S. E. Ketabchi, "Epidemiologic patterns of primary brain tumors in Iran," Asian Pacific Journal of Cancer Prevention, vol. 9, no. 2, pp. 361362, 2008.

[25] N. Mehrvar, A. Mehrvar, M. E. Akbari, and I. Qaddoumi, "Comprehensive analysis of Iranian reports of pediatric central nervous system tumors," Child's Nervous System, vol. 33, no. 9, pp. 1481-1490, 2017.

[26] M. Mehrazin, H. Rahmat, and P. Yavari, "Epidemiology of primary intracranial tumors in Iran, 1978-2003," Asian Pacific Journal of Cancer Prevention, vol. 7, no. 2, pp. 283-288, 2006.

[27] F. Salehpour, F. Mirzaei, A. Meshkini, S. Parsay, S. Salehi, and M. M. B. Asl, "Trends in primary brain tumors: a 5-year retrospective histologically confirmed study in Tabriz, Iran, 2011-2016," Asian Journal of Neurosurgery, vol. 14, no. 2, pp. 427-431, 2019.

[28] A. Almutrafi, Y. Bashawry, W. AlShakweer, M. al-Harbi, A. Altwairgi, and S. al-Dandan, "The epidemiology of primary central nervous system tumors at the National Neurologic Institute in Saudi Arabia: a ten-year single-institution study," Journal of Cancer Epidemiology, vol. 2020, Article ID 1429615, 9 pages, 2020.

[29] D. N. Louis, A. Perry, G. Reifenberger et al., "The 2016 World Health Organization classification of tumors of the central nervous system: a summary," Acta Neuropathologica, vol. 131, no. 6, pp. 803-820, 2016.

[30] D. Forman, F. Bray, D. H. Brewster et al., Cancer Incidence in Five Continents, Vol. X, Glossary of Terms. IARC Scientific Publications, No. 164, Lyon, IARC, 2013.

[31] F. Bray, A. H. Loos, S. Tognazzo, and C. La Vecchia, "Ovarian cancer in Europe: Cross-sectional trends in incidence and mortality in 28 countries, 1953-2000," International Journal of Cancer, vol. 113, no. 6, pp. 977-990, 2005.

[32] S. Hasanpour-Heidari, N. Jafari-Delouei, N. Shokoohifar et al., "Completeness and accuracy of death registry data in Golestan, Iran," Archives of Iranian Medicine, vol. 22, no. 1, pp. 1-6, 2019.

[33] G. Mohammadi, M. E. Akbari, Y. Mehrabi et al., "Estimating completeness of cancer registration in Iran with capturerecapture methods," Asian Pacific Journal of Cancer Prevention, vol. 17, Supplement 3, pp. 93-99, 2016.

[34] Q. T. Ostrom, H. Gittleman, G. Truitt, A. Boscia, C. Kruchko, and J. S. Barnholtz-Sloan, "CBTRUS statistical report: primary brain and other central nervous system tumors diagnosed in the United States in 2011-2015," Neuro-Oncology, vol. 20, Supplement 4, pp. iv1-iv86, 2018.

[35] A. Miranda-Filho, M. Pineros, I. Soerjomataram, I. Deltour, and F. Bray, "Cancers of the brain and CNS: global patterns and trends in incidence," Neuro-Oncology, vol. 19, no. 2, pp. now166-now280, 2016.

[36] J. L. Fisher, J. A. Schwartzbaum, M. Wrensch, and J. L. Wiemels, "Epidemiology of brain tumors," Neurologic Clinics, vol. 25, no. 4, pp. 867-890, 2007.

[37] S. Hoffman, J. M. Propp, and B. J. McCarthy, "Temporal trends in incidence of primary brain tumors in the United States, 1985-1999," Neuro-Oncology, vol. 8, no. 1, pp. 27-37, 2006.

[38] M. Wrensch, Y. Minn, T. Chew, M. Bondy, and M. S. Berger, "Epidemiology of primary brain tumors: current concepts and review of the literature," Neuro-Oncology, vol. 4, no. 4, pp. 278-299, 2002.
[39] M. Pineros, M. S. Sierra, M. I. Izarzugaza, and D. Forman, "Descriptive epidemiology of brain and central nervous system cancers in Central and South America," Cancer Epidemiology, vol. 44, Supplement 1, pp. S141-S149, 2016.

[40] M. Darabi, M. Asadi lari, A. Motevalian, A. Motlagh, S. Arsang-Jang, and M. Karimi Jaberi, "Trends in gastrointestinal cancer incidence in Iran, 2001-2010, with joinpoint analysis," Epidemiology and Health, vol. 38, article e2016056, 2016.

[41] F. Koohi, H. Salehiniya, R. Shamlou et al., "Leukemia in Iran: epidemiology and morphology trends," Asian Pacific Journal of Cancer Prevention, vol. 16, no. 17, pp. 7759-7763, 2015.

[42] R. Pakzad, H. Rafiemanesh, M. Ghoncheh et al., "Prostate cancer in Iran: trends in incidence and morphological and epidemiological characteristics," Asian Pacific Journal of Cancer Prevention, vol. 17, no. 2, pp. 839-843, 2016.

[43] N. Ghotbi, A. Ohtsuru, Y. Ogawa et al., "Pediatric CT scan usage in Japan: results of a hospital survey," Radiation Medicine, vol. 24, no. 8, pp. 560-567, 2006.

[44] J. D. Mathews, A. V. Forsythe, Z. Brady et al., "Cancer risk in 680,000 people exposed to computed tomography scans in childhood or adolescence: data linkage study of 11 million Australians," BMJ, vol. 346, no. may21 1, article f2360, 2013.

[45] S. Mirbaha, M. Forouzanfar, A. Saberinia, A. Salimi, H. Kariman, and M. Farmahini Farahani, "The financial burden of imaging tests conducted in the emergency department of a teaching hospital: a brief report," Journal of Emergency Practice and Trauma, vol. 6, no. 1, pp. 43-46, 2020.

[46] R. Fuentes-Raspall, M. Solans, A. Roca-Barcelo et al., "Descriptive epidemiology of primary malignant and non-malignant central nervous tumors in Spain: results from the Girona Cancer Registry (1994-2013)," Cancer Epidemiology, vol. 50, pp. 1-8, 2017.

[47] G. Edgren, L. Liang, H. O. Adami, and E. T. Chang, "Enigmatic sex disparities in cancer incidence," European Journal of Epidemiology, vol. 27, no. 3, pp. 187-196, 2012.

[48] G. Roshandel, A. Ghanbari-Motlagh, E. Partovipour et al., "Cancer incidence in Iran in 2014: results of the Iranian National Population-based Cancer Registry," Cancer Epidemiology, vol. 61, pp. 50-58, 2019.

[49] A. Wigertz, S. Lonn, J. Schwartzbaum et al., "Allergic conditions and brain tumor risk," American Journal of Epidemiology, vol. 166, no. 8, pp. 941-950, 2007.

[50] E. K. Cahoon, P. D. Inskip, G. Gridley, and A. V. Brenner, "Immune-related conditions and subsequent risk of brain cancer in a cohort of 4.5 million male US veterans," British Journal of Cancer, vol. 110, no. 7, pp. 1825-1833, 2014. 